\title{
Use of IUDs for emergency contraception: current perspectives
}

This article was published in the following Dove Press journal:

Open Access Journal of Contraception

25 August 2014

Number of times this article has been viewed

\section{Rebecca McKay' \\ Lynne Gilbert ${ }^{2}$}

'Department of Obstetrics and Gynaecology, Peterborough City Hospital, Peterborough, Cambridgeshire, United Kingdom; ${ }^{2}$ Department of Contraception and Sexual Health, Cambridgeshire Community Services NHS Trust, Cambridge, Cambridgeshire, United Kingdom
Correspondence: Rebecca McKay Department of Obstetrics and Gynaecology, Peterborough City Hospital, Peterborough, Cambridgeshire, PE3 9GZ, United Kingdom Tel+44I733678000

Email rebecca.mckay@pbh-tr.nhs.uk
Abstract: Emergency contraception is an essential intervention for the prevention of unplanned pregnancy worldwide. The copper intrauterine device (IUD) is highly effective at preventing pregnancy after unprotected sex or contraceptive failure. Unfortunately, its usage in this context is low and far exceeded by hormonal forms of emergency contraception. These have higher failure rates and, unlike the IUD, are not effective post-fertilization. This review aims to summarize the literature surrounding IUD use as emergency contraception, contrast it with the hormonal options, and provide suggestions for increased usage.

Keywords: levonorgestrel, ulipristal acetate, copper intrauterine device

\section{Prologue}

Preparation for this review involved scoping searches to identify relevant papers, including local, national, and international sources. Systematic searches were undertaken using MEDLINE. Search terms used were "IUD”, “intrauterine contraception", "emergency contraception", "hormonal emergency contraception", "Levonelle", "levonorgestrel", "ellaOne", and "ulipristal acetate". There was no attempt to comprehensively search gray literature, although selected conference presentations were occasionally referenced. Any publications after January 2014 were not included.

\section{Introduction}

Unplanned pregnancies are common and a global concern. In 2008, an estimated 41\% of pregnancies worldwide were unplanned, with the highest rates seen in developing countries. ${ }^{1}$ Even in parts of the developed world, where highly effective methods of regular contraception are available and increasingly accessible, the proportion of conceptions that are unplanned is high - for example, up to one-half in the USA. ${ }^{2}$ Frequently arising from either nonuse or inconsistent use of a regular method, they represent a failure of primary prevention and underline the need for secondary preventative strategies in the form of emergency contraception.

In Britain, the findings of the third National Survey of Sexual Attitudes and Lifestyles (Natsal-3) 3 indicate that $54.8 \%$ of pregnancies with a known outcome were planned, with the remainder being unplanned $(16.2 \%)$ or ambivalent $(29 \%) .{ }^{3}$ Of pregnancies that were aborted, $57.1 \%$ were unplanned. Comparisons with previous studies ie Natsal-1 (1990) and Natsal-2 (2000) ${ }^{4,5}$ reveal generational changes, with a decrease in the median age for respondents first time engaging in sexual intercourse, and an increase in the median age for first cohabitation and first birth. The authors of 
NATSAL- 3 " conclude that "a heterosexually active woman in Britain might now spend some 30 years of her life needing to avert unplanned pregnancy".

\section{When is emergency contraception needed?}

While unprotected sexual intercourse (UPSI) and condom failure are the commonest indication for emergency contraception, errors in the usage of other regular methods of contraception also generate the need for emergency measures. These are indicated in Table 1 and are based on UK practice as advocated by the FSRH.
Conception is critically dependent on the timing of intercourse in relation to ovulation and is most likely to occur when the intercourse is in the 48 hours preceding ovulation, with a negligible risk in the first 3 days of the cycle. ${ }^{6}$ The key event of ovulation is difficult to predict even in women with natural regular cycles. If natural cycles are irregular or are suspended by the use of a hormonal method of contraception, ovulation, and therefore risk of pregnancy, is even more difficult to determine. A woman may make a judgment about her need for emergency contraception by trying to quantify the risk of becoming pregnant. The importance attached to this measure will be

Table I Indications for emergency contraception when regular contraception fails

\begin{tabular}{|c|c|}
\hline Method & Indication \\
\hline Combined oral & $\begin{array}{l}\text { - When efficacy is compromised: } \\
\text { Two or more pills missed (or compromised by diarrhea and vomiting) in the first week of the pack } \\
\text { and UPSI has occurred in week I or during the preceding pill-free interval. } \\
\text { As above, with an error in last week of penultimate pack. } \\
\text { - UPSI during use of an enzyme-inducing drug or in the } 28 \text { days following cessation. } \\
\text { - When quick starting: } \\
\text { After day } 5 \text { of cycle - UPSI in first } 7 \text { days. } \\
\text { - After EHC: } \\
\text { - UPSI in first } 7 \text { days after levonorgestrel. } \\
\text { - UPS first } 14 \text { days after ulipristal acetate. }\end{array}$ \\
\hline Combined ring or patch & $\begin{array}{l}\text { - When efficacy is compromised: } \\
\text { - UPSI during extended ring- or patch-free interval. } \\
\text { UPSI during extended ring or patch use. } \\
\text { - UPSI during use of an enzyme-inducing drug or in the } 28 \text { days following cessation. } \\
\text { When quick starting: } \\
\text { After day } 5 \text { of cycle - UPSI in first } 7 \text { days. } \\
\text { - Ufter EHC: } \\
\text { - UPSI in first } 7 \text { days after levonorgestrel. }\end{array}$ \\
\hline Progestogen-only oral & $\begin{array}{l}\text { - When efficacy is compromised: } \\
\text { compromised by diarrhea and/or vomiting and additional precautions have not been used until two } \\
\text { further pills have been taken correctly. } \\
\text { - UPSI during use of an enzyme-inducing drug or in the } 28 \text { days following cessation. } \\
\text { - When quick starting: } \\
\text { After day } 5 \text { of cycle - UPSI in first } 2 \text { days. } \\
\text { After EHC: } \\
\text { - UPSI in first } 2 \text { days after levonorgestrel. } \\
\text { - UPSI in first } 9 \text { days after ulipristal acetate. }\end{array}$ \\
\hline
\end{tabular}

Progestogen-only injectable, eg, depot medroxyprogesterone acetate

Progestogen-only implant

Levonorgestrel intrauterine system
- UPSI in first 7 days of use when started after day 5 of cycle or quick-started after EHC.

- UPSI more than 14 weeks since last injection.

- UPSI in first 7 days of use when not fitted in first 5 days of cycle or quick-started after EHC.

- UPSI beyond duration of licensed period, ie, 3 years.

- UPSI in first 7 days of use when not fitted in first 7 days of cycle.

- UPSI after 5 years of use, ie, out of license (except when fitted in a woman aged 45 years or over).

- Removal within 7 days of UPSI.

Abbreviations: EHC, emergency hormonal contraception; UPSI, unprotected sexual intercourse. 
unique to her and may vary in the same woman according to her current context. Each case must therefore be individualized according to need and take into account the woman's preferences.

\section{The options for emergency contraception}

Emergency contraception can be oral hormonal or the copper intrauterine device (IUD). Of these, only the IUD works after fertilization. While a judicial review in the UK in $2002^{7}$ ruled that pregnancy begins at implantation, and that emergency contraceptives are not therefore abortifacient, a discussion of the mechanisms of action is essential. Individuals who hold the contrary view that life begins at fertilization who are also opposed to abortion would find the IUD unacceptable.

\section{Oral options for emergency contraception}

There are currently two commonly used oral options. Levonorgestrel (LNG) 1,500 mg was licensed in 1999 and was the only option available until ulipristal acetate (UPA) $30 \mathrm{mg}$ (ellaOne ${ }^{\circledR}$; HRA Pharma, Paris, France) was licensed in the UK in May 2009. UPA is a selective progesterone receptor modulator that binds strongly to progesterone receptors in target tissues, eg, uterus, cervix, ovaries, and hypothalamus, and exerts tissue-selective agonist, antagonist, and partial agonist effects. In the context of emergency contraception, both LNG and UPA appear to work primarily by inhibiting or delaying ovulation. ${ }^{8}$ In vitro studies have shown an effect of UPA on delaying endometrial maturation, but the significance of this has not been established. ${ }^{9}$ A crucial event in the process of ovulation is the luteinizing hormone (LH). Whereas LNG is ineffective after the onset of the LH surge, UPA administered between the onset and the peak of the LH surge can delay follicular rupture for at least 5 days ${ }^{10}$ and appears to be more effective than LNG around the time of ovulation. ${ }^{11,12}$ Moreover, as the interval since unprotected intercourse increases, the efficacy of LNG declines. ${ }^{13} \mathrm{UPA}$, however, continues to be effective for up to 120 hours, with no decline in efficacy over this time period, ${ }^{14}$ and is significantly more effective than LNG when 72 to 120 hours have elapsed since unprotected intercourse. Figure 1 illustrates the "window of opportunity" for the action of the three emergency contraception options.

In some countries (eg, the People's Republic of China, Russia, Vietnam), mifepristone, which is widely used in medical abortions, is licensed at a lower dosage for emergency contraception. Mifepristone is a progesterone and

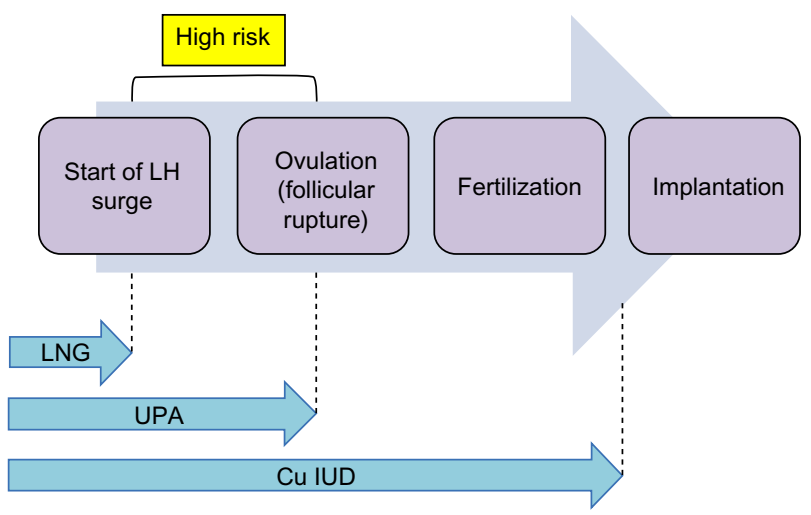

Figure I Window of opportunity for action of the three emergency contraception options.

Abbreviations: IUD, intrauterine device; LH, luteinizing hormone; LNG, levonorgestrel; UPA, ulipristal acetate.

glucocorticoid antagonist derived from norethindrone. It acts to delay ovulation and may cause endometrial changes, which can prevent implantation. Its efficacy is estimated to be approximately $85 \%$. The Yuzpe regimen (combined estrogen and progestogen) is also still used, but is associated with significantly more side effects than other hormonal methods.

\section{Copper IUDs}

A systematic review on mechanisms of action of IUDs demonstrated both pre- and post-fertilization effects with a failure rate of $1 \%-2 \%$ when used as a regular contraception. ${ }^{15,16}$ Copper is toxic to the ovum and sperm, and is therefore immediately effective for acts of intercourse that follow the insertion of the IUD. However, if intercourse precedes the IUD insertion, fertilization may have already occurred, and such use postcoitally depends on an anti-implantation effect. To legally insert a copper IUD as an emergency contraception, it is essential to avoid insertion into a uterus that could have an early implanted pregnancy. In a study of 221 women trying to conceive, the mean time from ovulation to implantation was 9 (range 6-18) days. ${ }^{17}$ It is therefore safe to fit an emergency IUD up to 5 days after the first episode of UPSI that cycle wherever the woman is in her cycle. As fertilization cannot occur until ovulation, it is safe to fit an emergency IUD within 5 days of the earliest estimated day of ovulation. However, wherever a woman is in her cycle it is also safe to fit an IUD if all acts of intercourse that cycle have been within the past 5 days. ${ }^{18}$ It is assumed that the post-ovulation, luteal phase is fairly constant at 14 days, and subtracting this from the cycle gives the earliest likely day of ovulation (Figure 2). While some women may ovulate later in their cycle, this calculation ensures safe limits by accommodating the worst-case scenario. 


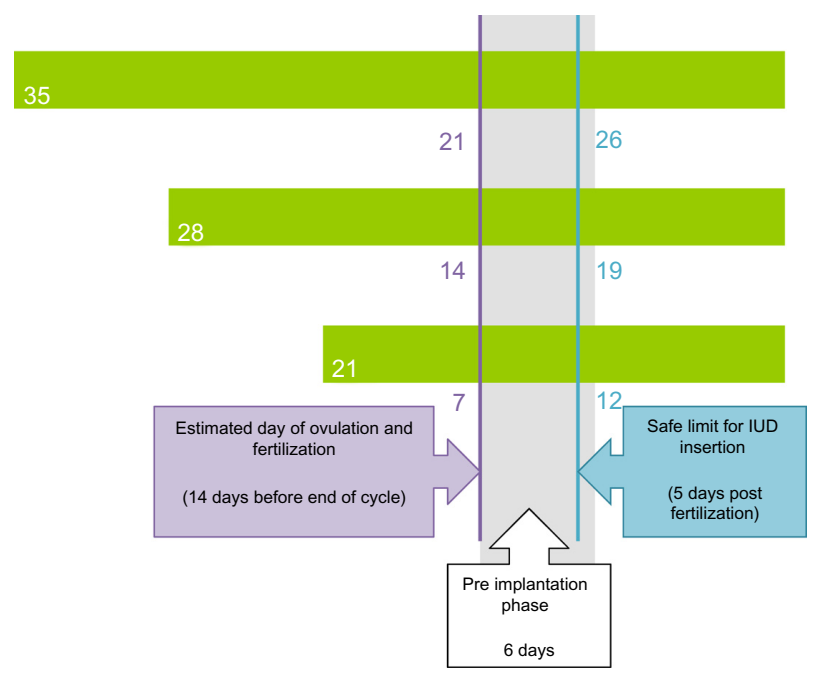

Figure 2 Calculation of safe limits for intrauterine device (IUD) insertion with three different cycle lengths.

Note: Numbers indicate day of cycle.

In women experiencing potential failures of hormonal methods of contraception, calculating the safe limits for a copper IUD insertion is more complex. With combined methods, the timing of ovulation after loss of protection can be estimated, and it is therefore necessary to establish when the woman was last protected. For a pill user, this is after the most recent run of seven pills taken correctly and consecutively, at which point the ovaries are suppressed. For pills containing at least $30 \mu \mathrm{g}$ estrogen, ovulation may occur 10 days after this point. A copper IUD may therefore be safely inserted for any acts of unprotected intercourse up to 15 days after the end of ovarian suppression (or 14 days for pills containing less than $30 \mu \mathrm{g}$ estrogen). However, with potential failures of progestogen-only methods of contraception, ovulation cannot be estimated, and in this case a copper IUD can only be fitted safely up to 5 days after unprotected intercourse.

While these calculations reflect current recommendations of the World Health Organization and other professional bodies, ${ }^{19-21}$ such as Faculty of Sexual and Reproductive Healthcare ([FSRH] UK) and the Centers for Disease Control and Prevention (USA), they were challenged in a recent study $^{22}$ that suggests that the IUD is as safe and effective as emergency contraception whenever it is inserted in the menstrual cycle, provided a suitably sensitive pregnancy test is negative. This statement is based on the finding that there were no pregnancies in a group of women who had the IUD inserted outside the conventional "safe window". ${ }^{19}$ However, the safe window was established by calculating ovulation day from day 1 of the preceding menses, and the number of women in this group was very small. Clearly, any change to accepted practice that widens the window of opportunity for fitting an emergency IUD is welcome but will be critically dependent on a pregnancy test that can guarantee that implantation has not occurred. Without this, the potential to cause an abortion by extending the safe period for IUD insertion throughout the cycle has significant legal implications. As the routinely used urine pregnancy tests can give false negative results, current recommendations are unlikely to change, and practitioners are advised to follow the guidance of their professional bodies.

\section{The advantages and disadvantages of hormonal emergency contraception versus copper IUDs}

What potential do existing emergency contraceptive options (oral hormonal and copper IUDs) have for preventing unplanned pregnancies? The answer is more complex than a simple comparison of the efficacy of each, and is likely to differ when addressed from the individual and population perspectives. While innate efficacy may set an upper limit, many other factors, such as safety, ease of use, availability, acceptability, and cost, will operate to significantly moderate the extent to which the potential to reduce unplanned pregnancies is realized.

In any discussion on efficacy, it is important to distinguish between absolute and relative measures, and to consider the duration of efficacy. ${ }^{23}$ The ideal method is one that works for at least the lifetime of sperm and, ensures that the fertile window is covered throughout the cycle up until implantation. As depicted in Figure 2, the copper IUD is the only option that satisfies this criterion.

Efficacy can be defined as the ratio between the observed and expected pregnancies. Measurements of absolute efficacy require a suitably powered, randomized, and placebocontrolled trial in which the pregnancy rates with and without different emergency contraceptive interventions are compared. As pregnancy is the outcome of treatment failure, such a trial is clearly unethical. While the number of pregnancies that occur after an intervention is relatively easy to determine, the pregnancy rate without treatment must be estimated, and such estimates are complex and involve several assumptions. The most accurate estimates are those in which the chance of conception from a given act of intercourse is related to the interval between intercourse and ovulation and, crucially, in which ovulation is identified by validated endocrine markers. ${ }^{24}$ Some studies on efficacy ${ }^{2,20}$ have used a much cruder assessment, in which ovulation and the stage in the cycle 
when intercourse occurred is determined from cycle length and the date of onset of the last menstrual period. However, even in women with apparently regular cycles, ovulation can be variable and occur later in the cycle than expected. Moreover, women's recall of timing of episodes of intercourse and their self-reported menstrual staging is often inconsistent with that indicated by endocrine data. ${ }^{25,26}$

Despite the accepted complexities in measuring the absolute efficacy of emergency contraception, current evidence suggests that, of the two most widely used hormonal options, UPA is more effective than LNG. ${ }^{4}$ What is very clear, however, is that the copper IUD is significantly more effective than any other option. A systematic review of the use of the copper IUD for emergency contraception indicates a failure rate of $0.09 \%$. Crucially, it is effective in the 48 hours before ovulation when the risk of conception is greatest and when hormonal options may have no or minimal effect. ${ }^{27,28}$ It is also unaffected by body mass index (BMI), which appears to have a negative effect on the efficacy of hormonal methods. ${ }^{29}$ Using statistical modeling techniques on data from randomized trials of UPA and LNG, it appears that obese women have a threefold greater risk of pregnancy than women of normal BMI, and the BMI at which treatment makes no difference to the risk of conception is $26 \mathrm{~kg} / \mathrm{m}^{2}$ for LNG and $35 \mathrm{~kg} / \mathrm{m}^{2}$ for UPA. ${ }^{29}$

While there is no doubt that the copper IUD is almost $100 \%$ effective in preventing unplanned pregnancy, arguments for its cost-effectiveness, particularly in comparison to the other options, are more complex. Such an assessment requires creating a balance sheet recording the costs of providing the method against the savings made by averting an unplanned pregnancy. As this, in turn, depends on knowing the expected pregnancy rate without intervention, which, as previously discussed, is difficult to determine, the calculations are fraught with problems. Moreover, while direct costs, such as personnel time involved in providing the method; consumables such as the drugs, device, etc; and provision of antenatal care or an abortion, are relatively easy to quantify, there are also very significant indirect and intangible costs where only crude assessments involving many assumptions and extrapolations are possible. These include a mixture of diverse issues relating to the individual and the wider society, such as the emotional and social impact of unplanned pregnancy and the effects on education, workforce, economic productivity, and welfare services. Complexities aside, analyses have demonstrated that the copper IUD is a cost-effective method of contraception, ${ }^{30}$ although benefits accrued will clearly depend on length of use. Although these analyses do not specifically assess the use of the IUD as emergency contraception, the conclusion is likely to be valid, as, in the emergency situation, the risk of conception and therefore the potential savings are likely to be higher than when an IUD is initiated as a regular method.

Of key importance to a discussion on cost-effectiveness is the need for ongoing contraception. While the hormonal methods only address preceding risks, the copper IUD, if retained, can provide immediate and highly effective contraception for up to 10 years. The value of this is underlined by studies demonstrating the persistent and even increased risk of pregnancy after the use of hormonal methods.

As the effect of hormonal methods is to disrupt or delay ovulation for at least the longevity of sperm, in so doing they may shift the risk to later in the cycle. Many women, up to $30 \%$, have further unprotected intercourse between receiving hormonal emergency contraception and their next bleed and, as a result, are more likely to become pregnant. ${ }^{31}$ Of 4,500 women reporting further episodes of unprotected intercourse after receiving hormonal emergency contraception, the relative risk of pregnancy was 2.61 when compared to women who had no further intercourse prior to the next menses. ${ }^{32}$ Guidance on "quick starting" hormonal methods of contraception ${ }^{33}$ after hormonal emergency contraception recognizes the importance of protecting subsequent acts of intercourse as soon as possible. However, this practice may not be widely used. A study from a specialist contraceptive service in Scotland reported that only $23 \%$ of women using no method or condoms at presentation for emergency contraception received supplies of an effective ongoing method (pills, patch, injectable), and that two-thirds of women chose to use condoms. ${ }^{34}$ When these methods are quick started, they are not immediately effective. After LNG, additional precautions are advised for 2 days when commencing the progestogen-only pill and for 7 days when commencing a combined hormonal method or the progestogen-only implant. As a progesterone antagonist, UPA may compromise the efficacy of subsequent hormonal methods and, accordingly, an additional 7 days of extra precautions is advised ( 9 days for progestogen-only pill and 14 days for combined hormonal methods and the progestogen-only implant).

Safety may be an issue for both health care providers and patients. How realistic are such concerns? Data for both hormonal and intrauterine methods are reassuring. The only absolute contraindication to fitting an emergency IUD is pregnancy (World Health Organisation, Medical Eligibility Criteria). Potential safety concerns related to the IUD are perforation and infection. Perforation is an uncommon event, 
occurring in approximately one in 1,000 procedures. Risk factors include inexperience of the fitter; recent delivery, especially if breastfeeding and involving a cesarean section; and anatomical issues such as fixed retroversion of the uterus. Similarly, the risk of infection following insertion of an IUD is low, at $0 \%-5 \%$. It is only elevated during the first 20 days after insertion, ${ }^{35,36}$ indicating an association with preexisting infection. Insertion in the presence of asymptomatic chlamydia or gonorrhea can be considered safe, as it is the presence of infection not the placement of the device that increases the risk of pelvic inflammatory disease (PID). ${ }^{37}$ Should PID develop, removal of the device is not indicated unless there is failure to respond to treatment. Current guidelines ${ }^{19}$ do, however, advise against insertion in the presence of PID, clinical cervicitis, or symptomatic infection with chlamydia or gonorrhea. As the indication for emergency contraception, ie, unprotected intercourse, is also a risk factor for sexually transmitted infection (STI), current guidelines ${ }^{19}$ advocate a risk assessment with screening and prophylactic treatment as appropriate. This would be particularly important in victims of sexual assault who may be at particularly high risk of STIs.

All emergency contraception options are associated with adverse side effects, either real or perceived, which have the potential to limit the use of emergency contraception. Hormonal side effects such as nausea, vomiting, headache, and abdominal pain will be short-lived. As an invasive procedure, fitting an IUD may be associated with pain at the time of the procedure, although procedural practices may minimize this. ${ }^{48}$ If retained, menses are likely to be heavier, more prolonged, and with an increased risk of intermenstrual bleeding. Such side effects often improve over the first few months of use and of course are not relevant if the device is to be used solely for emergency contraception. It is often assumed that fitting IUDs in young women, especially those who are nulliparous, is problematic. However, published experience is encouraging. ${ }^{38}$ In the study by Bayer et al, adolescents experienced minimal complications and similar rates of successful insertion as older women. Although rates of discontinuation were higher than in older women, they were similar for parous and nulliparous teenagers and lower than reported for teenagers using other forms of contraception. ${ }^{38}$ Figure 3 illustrates the pros and cons of the various types of emergency contraception.

\section{What do women actually use?}

The United Kingdom Omnibus Survey 2008-9 for the Office for National Statistics showed that, of the women surveyed, only $7 \%$ had used emergency contraception in the previous year and none had had an IUD fitted. ${ }^{39}$ Overall, the use of emergency contraception is low, even among women not planning to conceive. In a study of women seeking termination of pregnancy in Scotland, 90\% had an unintended pregnancy but only $11.8 \%$ had used emergency contraception. ${ }^{40}$

A range of studies from different services in the UK show wide variability in the uptake of the different methods of emergency contraception, particularly the copper IUD. In a specialist Contraception and Sexual Health (CASH) service in Edinburgh, ${ }^{34}$ only $2 \%$ of the women attending for emergency contraception accepted an IUD, compared to $5 \%$ in Liverpool ${ }^{40}$ and $15 \%$ in Cambridge. ${ }^{43}$ The FSRH guidance advocated that all eligible women should be offered an IUD, which should be fitted on the day of presentation if possible.

As UPA is relatively new in the UK and more expensive than LNG, access to UPA is inconsistent. Many services have developed their own protocols, ranging from unrestricted use, to use guided by a risk assessment or restricted use in women presenting between 72 and 120 hours after UPSI when LNG is unlicensed. A service in Liverpool that offers all methods in accordance with the FSRH found that $55 \%$ chose $\mathrm{LNG}$, $40 \%$ UPA, and $5 \%$ IUD. $^{41}$

Whatever the innate efficacy of a method, its potential to reduce the unintended pregnancy rate is clearly limited by poor uptake and invites consideration of possible causal factors. Whether a woman uses emergency contraception and which method she selects is subject to a wide array of influences. Some of these will be applicable to emergency contraception in general and others will be specific to the intrauterine option. These influences may reside with the patient or health care provider.

\section{Patient factors}

Of fundamental importance is women's knowledge of emergency contraception. In the United Kingdom Omnibus Survey 2008-9 for the Office for National Statistics, although $91 \%$ of women had heard of oral postcoital contraception, only $40 \%$ of women were aware of the emergency IUD. ${ }^{39}$ Detailed knowledge of the time limits for using these methods is needed, as underestimates may result in failure to access a method. Whereas $48 \%$ knew that pills could be used up to 72 hours after unprotected intercourse, only $13 \%$ were aware that the IUD may be used for up to 5 days after intercourse, and $43 \%$ did not know how long after intercourse an emergency IUD could be used. Even if they were aware of both options, many women overestimated the efficacy of oral methods. ${ }^{39}$ 


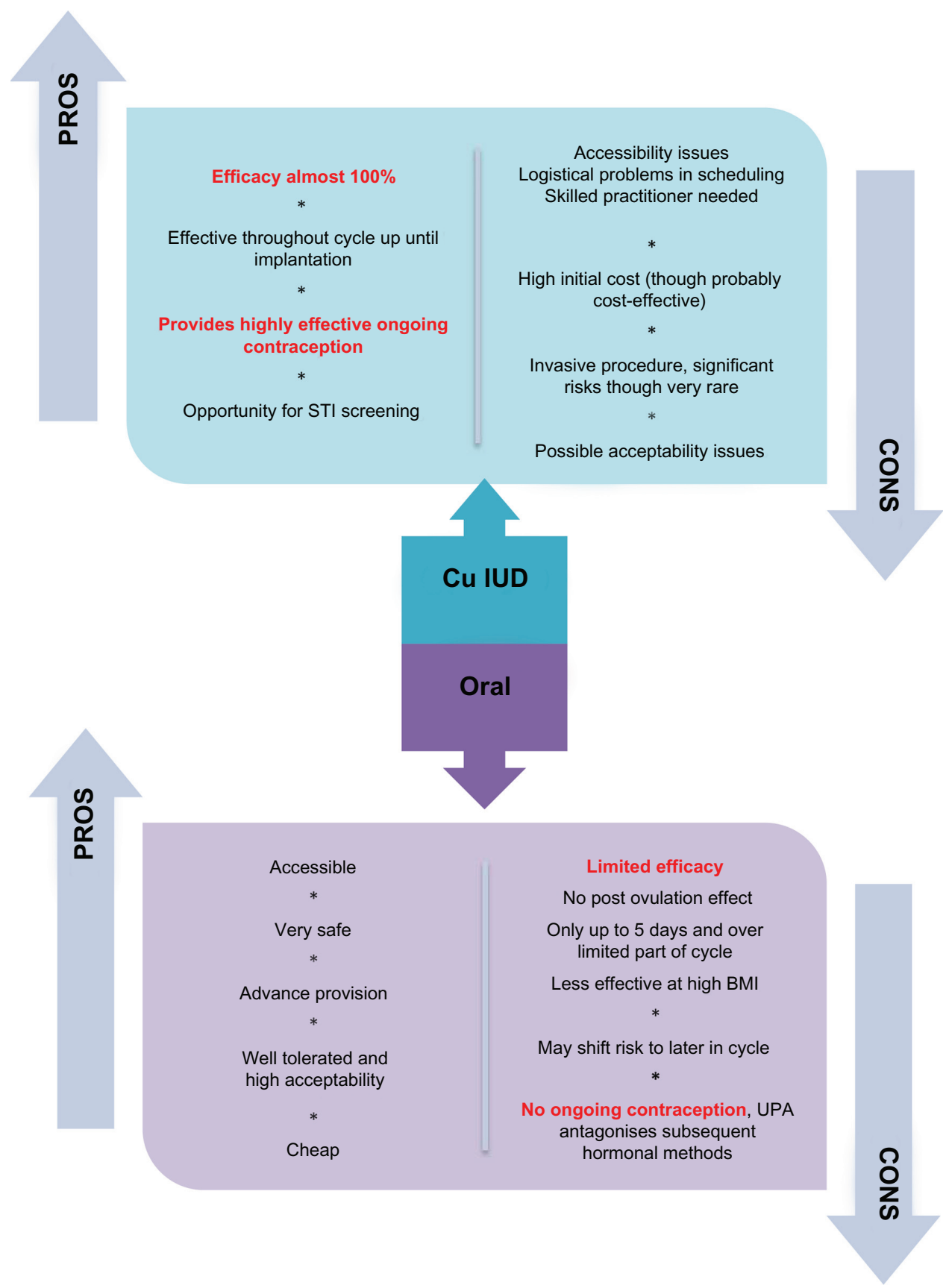

Figure 3 Comparison of pros and cons of hormonal methods and the Cu IUD.

Abbreviations: BMI, body mass index; IUD, intrauterine device; STI, sexually transmitted infection; UPA, ulipristal acetate.

Women's perceptions and often misconceptions about side effects are highly influential in their decision-making. ${ }^{44}$ Even with hormonal methods of emergency contraception, qualitative studies ${ }^{42}$ have demonstrated that women have concerns and believe myths about harmful hormonal load and effects on future fertility. Similarly, in a qualitative study ${ }^{40}$ exploring women's attitudes to intrauterine contraception among women seeking termination of pregnancy, $34 \%$ agreed with the statement that insertion was painful (especially women under the age of 19 years); $23.6 \%$ considered that it could move around inside the body; and $16 \%$ felt there was a good chance of damage to the womb and creation of a breeding ground for infection. Familiarity with a method and what is perceived as normal (eg, using the pill as opposed to an IUD) encourages use of that method, and the negative experiences of peers and relatives, even those heard secondhand, contribute to negative perceptions. Even the terminology of "long-acting" as opposed 
to "long-lasting" can have negative connotations. ${ }^{45}$ What is perceived as "normal" shows large geographic variation. While $6 \%$ of women in the UK use the copper IUD (Office for National Statistics), it is much more common (37\%) among women in East Asia. ${ }^{46}$

Women often fear having the IUD fitted, and techniques to reduce the pain of fitting could increase uptake. A study in Mexico investigated whether using pre-procedure misoprostol reduced the pain of insertion specifically in nulliparous women. This showed disappointing results, with no improvement in discomfort. ${ }^{47}$ A review published this year $(2014)^{48}$ provided some practical suggestions for avoiding or alleviating pain during IUD fitting. This included emphasis on the importance of good patient support (so-called "vocal local" or verbal anesthesia). Women's anxiety about the procedure may contribute to higher levels of perceived pain. Despite the fact that no prophylactic pharmacological intervention has been adequately evaluated to support routine use for pain reduction during or after IUD insertion, the use of local anesthetic is also advised if there is cervical stenosis, difficulty measuring the uterus, or on patients' request. This review also stressed the importance of optimal patient positioning on a gynecology couch with leg rests.

Women's perceptions are also relevant to how they assess and view the risk of pregnancy. This in turn influences their decision to use emergency contraception. Women often underestimate their risk of conception. In a study of women attending four abortion centers in France, 89\% of women were aware of emergency contraception and $38.5 \%$ were aware of a risk at the time they conceived, but almost half of those who were aware of a risk subsequently minimized it and decided not to access emergency contraception. ${ }^{49}$ More subtle considerations, such as perceived longevity of a relationship, may also influence a woman's willingness to select the copper IUD. ${ }^{50}$ In the small study by Wright et al, women considered the use of contraception in the context of each relationship and associated long-acting methods with long-term relationships. ${ }^{50}$ This, and other studies from USA, ${ }^{51-53}$ not only highlight lack of knowledge as a significant factor in the underuse of the emergency IUD, but also indicate that around one in eight women would be interested if the procedure could be done on the day of presentation, involved one visit, and was free of charge.

\section{Health care provider factors}

A final determinant limiting the potential of emergency contraception to reduce unintended pregnancies is availability. Hormonal options can be purchased in over 140 countries and, in half of these, there have been initiatives to increase access by allowing supply without a prescription (sometimes free of charge) either from a pharmacist or directly over the counter. ${ }^{54}$ In some countries, it is also possible to obtain pills in advance of need. Such advance provision has generated concerns that women would be more likely to take risks, be less likely to use a regular method, use emergency pills more often, and be at increased risk of STIs. A systematic review of advance provision concludes that these fears have not been realized, ${ }^{55}$ although a Cochrane Review found some evidence that women with emergency pills may use them multiple times. ${ }^{56}$ Rather surprisingly, review of many studies has concluded that, although increased access to emergency contraceptive pills has increased usage, this has not led to a reduction in unplanned pregnancy or abortion. ${ }^{57}$ To maximize the potential of these initiatives, appropriate signposting is needed to facilitate the uptake of the more effective emergency IUD and to address the need for ongoing contraception. A study in Scotland reported that, of pharmacies offering hormonal emergency contraception, only $43 \%$ discussed the need for ongoing contraception. ${ }^{58}$ Introducing an educational program for pharmacists and the development of a clear referral pathway has resulted in a 17-fold increase in referrals to a specialist contraceptive service and a threefold increase in the uptake of the emergency IUD. ${ }^{59}$

The impact of any measures to improve uptake of the emergency IUD, such as increasing women's knowledge, addressing misconceptions, and improving referral pathways, is inevitably dependent on those who have the ability to provide the service. Surveys exploring the knowledge, attitudes, and practices of practitioners in the field of contraception have yielded disappointing and surprising results. A UK study of a group of general practices in the West Midlands assessed 718 consultations for emergency contraception and found that the IUD was discussed in only $1.4 \%{ }^{60}$ In a survey from USA of 816 clinicians involved in the California State family planning program, ${ }^{61}$ in which contraception is free to low-income women and thus cost is not an issue, $85 \%$ never recommended the copper IUD for emergency contraception. Although more than $93 \%$ of obstetricians/gynecologists were skilled to fit the device and frequently counseled patients about the intrauterine method for regular contraception, they were no more likely to recommend the device for emergency contraception than other physicians. ${ }^{54}$ These findings are explained, at least in part, by concerns about clinic scheduling and protocols requiring two clinic visits to allow for pre-insertion swabs, despite the evidence that insertion in the presence of asymptomatic 
chlamydial or gonorrheal infection is safe.$^{37}$ Furthermore these findings indicate a significant need for clinician training and education.

Reassuringly, studies have shown that continuing education for the providers can improve uptake for patients. A study in Cambridge, $\mathrm{UK}^{43}$ showed that creating an algorithm to guide risk assessment for emergency contraception led to an increase in clinicians discussing and offering the IUD. Among high-risk women, 93\% were offered the IUD compared with $59 \%$ prior to the algorithm. ${ }^{43}$ Further study by the same group showed that continued teaching had improved uptake from $8 \%$ with the initial introduction of the algorithm to a sustained increase of $17 \%{ }^{62}$

\section{Conclusion}

In concluding this review, it is worth reflecting on why unplanned pregnancy is such an important issue that merits our best efforts to maximize the potential of emergency contraception. For the woman, her family, the child, and the wider society, a wealth of global evidence demonstrates the frequent negative impact of unplanned pregnancy. Quite apart from the obvious economic arguments, there are significant health issues. While not all unplanned pregnancies are unwanted, abortion is a frequent consequence. Global estimates suggest that $48 \%$ of unplanned pregnancies end in induced abortion, $38 \%$ lead to unplanned births, and $13 \%$ result in spontaneous abortion. ${ }^{63}$ Unsafe abortion, particularly in the developing world, can have serious health consequences including infertility and maternal death. ${ }^{64}$

If a woman chooses to continue with the pregnancy, the lack of prenatal counseling and care in turn increases the risk of obstetric complications. ${ }^{65}$ Unplanned pregnancy in the developed world is often associated with adverse factors such as smoking, recent use of drugs and alcohol, and depression, all of which have negative outcomes for both the mother and the child. Mothers are more prone to pre- and postnatal depression; relationship breakdown is more likely; and the children are often of lower birth weight and have poorer mental and physical health during childhood. ${ }^{66,67}$

There is clearly an enduring need for emergency contraception, as UPSI is common, and regular methods, particularly those that are dependent on the user, can fail. To date, there is no evidence that, at a population level, increased access to hormonal emergency contraception has impacted significantly on the rate of unplanned pregnancies. Currently, the copper IUD, which is the most effective form of emergency contraception and the only one to provide immediate ongoing contraception, is regrettably the most underused.
Increased uptake of the IUD and, hopefully, consequent reduction of unplanned pregnancy will only occur if there is both user and provider education combined with improved access.

As to whether there are other methods of emergency contraception in development, UPA is the newest hormonal form of emergency contraception, and there is little evidence of any others in development. A recent study ${ }^{68}$ described a new IUD - the intrauterine ball - which is postulated to reduce perforation and malposition, and ease insertion. This has only been tested in 15 women, and not for emergency contraception, so common usage is a long way in the future.

Despite the undoubted value of emergency contraception, perhaps the real key to reducing unplanned pregnancies is education and primary prevention. As demonstrated in Natsal- $3,{ }^{3}$ unplanned pregnancies are much more strongly associated with educational attainment than socioeconomic status. By improving women's lives, and economic and employment prospects, education provides a powerful motivator to avoid an unplanned pregnancy.

Inevitably, the combination of measures for primary and secondary prevention will be insufficient to eliminate unplanned pregnancies and there will be continued demand for access to safe and legal abortion.

\section{Disclosure}

The authors report no conflicts of interest in this work.

\section{References}

1. Subgh S, Sedgh G, Hussain R et al. Unintended pregnancy: worldwide levels, trends and outcomes. Stud Fam Plann. 2010;41(4):241-50.

2. Mosher WD, Jones J, Abma JC et al. Intended and unintended births in the USA 1982-2010. National Health Statistics report. 2012:55.

3. Wellings $\mathrm{K}$, Jones $\mathrm{KG}$, Mercer $\mathrm{CH}$, et al. The prevalence of unplanned pregnancy and associated risk factors in Britain: findings from the third National Survey of Sexual attitudes and Lifestyles (Natsal-3). Lancet. 2013;382:1807-1816.

4. Wellings K, Field J, Johnson AM et al. Sexual Behaviour in Britain: The National Survey of Sexual Attitudes and Lifestyles. London: Penguin Books Ltd. 1994.

5. Wellings K, Nanchalal K, Macdowall W et al. 2001. Lancet. 358 (9296):1843-1850.

6. Wilcox AJ, Dunson DB, Weinberg CR, Trussell J, Baird DD. Likelihood of conception with a single act of intercourse: providing benchmark rates for assessment of post-coital contraceptives. Contraception. 2001;63:211-215

7. Department of Health. Judicial Review of Emergency Contraception. R v Secretary of State for Health (Defendant) \& (1) Schering Health Care Ltd (2) Family Planning Association (Interested Parties), Ex Parte John Smeaton (on behalf of The Society for the Protection of Unborn Children) (Claimant). 2002 EWCH 610 (Admin), 2002, Crim LR 665. 2003. Available from: http://webarchive.nationalarchives.gov.uk/+/ www.dh.gov.uk/en/Publichealth/Healthimprovement/Sexualhealth/ Sexualhealthgeneralinformation/DH_4063853. Accessed May 30, 2014. 
8. Glasier AF, Cameron ST, Fine PM, et al. Ulipristal acetate versus levonorgestrel for emergency contraception: a randomized noninferiority trial and meta-analysis. Lancet. 2010;375:555-562.

9. Stratton P, Levens ED, Hartog B, et al. Endometrial effects of a single early luteal dose of the selective progesterone receptor modulator CDB-2914. Fert Steril. 2010;93:2035-2041.

10. Stratton P, Hartog B, Hajizadeh N, et al. A single mid-follicular dose of CDB-2914, a new antiprogestin, inhibits folliculogenesis and endometrial differentiation in normally cycling women. Hum Reprod. 2000;15(5):1092-1099.

11. Brache V, Cochon L, Jesam C, et al. Immediate pre-ovulatory administration of $30 \mathrm{mg}$ ulipristal acetate significantly delays follicular rupture. Hum Reprod. 2010;25:2256-2263.

12. Noé G, Croxatto HB, Salvatierra AM, et al. Contraceptive efficacy of emergency contraception with levonorgestrel given before or after ovulation. Contraception. 2010;81:414-420.

13. Piaggo G, Kapp N, von Hertzen $\mathrm{H}$. Effect on pregnancy rates of the delay in administration of levonorgestrel for emergency contraception: a combined analysis of four WHO trials. Contraception. 2011;84:35-39.

14. Creinin MD, Schlaff WD, Archer DF, et al. Progesterone receptor modulator for emergency contraception: a randomized controlled trial. Ostet Gynecol. 2006;108:1089-1097.

15. Cleland K, Zhu H, Goldstuck N, Cheng L, Trussell J. The efficacy of intrauterine devices for emergency contraception: a systematic review of 35 years of experience. Hum Reprod. 2012;27(7):1994-2000.

16. Stanford JB, Mikolajczyk RT. Mechanisms of action of intrauterine devices: update and estimation of postfertilization effects. Am J Obstet Gynecol. 2002;187:1699-1708.

17. Wilcox AJ, Baird DD, Weinberg CR. Time of implantation of the conceptus and loss of pregnancy. $N$ Engl J Med. 1999;340:1796-1799.

18. [No authors listed]. Mechanism of action, safety and efficacy of intrauterine devices. Report of a WHO Scientific Group. World Health Organ Tech Rep Ser. 1987;753:1-91.

19. WHO (World Health Organisation). Medical eligibility criteria for contraceptive use. 2009 4th edition. P79. Geneva.

20. Faculty of Sexual and Reproductive Healthcare Clinical Guidance. Emergency Contraception, Clinical Effectiveness Unit. August 2011 (updated January 2012).

21. CDC: US Selected Practice recommendations for Contraceptive Use, 2013: Adapted from the World health Organisation Selected Practice Recommendations for Contraceptive Use, 2nd edition.

22. Turok DK, Godfrey EM, Wojdyla D, Dermish A, Torres L, Wu SC. Copper T380 intrauterine device for emergency contraception: highly effective at any time in the menstrual cycle. Hum Reprod. 2013;28(10):2672-2676.

23. Trussell J, Ellertson C, von Hertzen H, et al. Estimating the effectiveness of emergency contraceptive pills. Contraception. 2003;67(4): 259-265.

24. Wilcox AJ, Weinberg CR, Baird DD. Post-ovulatory ageing of the human oocyte and embryo failure. Hum Reprod. 1998;13:394-397.

25. Stirling A, Glasier A. Estimating the efficacy of emergency contraception - how reliable are the data? Contraception. 2002;66:19-22.

26. Novikova N, Weisberg E, Stanczyk FZ, Croxatto HB, Fraser IS. Effectiveness of levonorgestrel emergency contraception given before and after ovulation - a pilot study. Contraception. 2007;75: 112-118.

27. Brache V, Cochon L, Deniaud M, Croxatto HB. Ulipristal acetate prevents ovulation more effectively than levonorgestrel: analysis of pooled data from three randomized trials of emergency contraception regimens. Contraception. 2013;88:611-618.

28. Croxatto HB, Brache B, Cochon L, et al. The effects of immediate preovulatory administration of $30 \mathrm{mg}$ ulipristal acetate on follicular rupture. 8th Congress of the European Society of Gynecology; September 10-13, 2009; Rome.

29. Glasier A, Cameron ST, Blithe D, et al. Can we identify women at risk of pregnancy despite using emergency contraception? Data from randomized trials of ulipristal acetate and levonorgestrel. Contraception. 2011;84:363-367.
30. Trussell J, Lalla AM, Doan QV, Reyes E, Pinto L, Gricar J. Cost effectiveness of contraceptives in the United States. Contraception. 2009;79:5-14

31. von Hertzen H, Piaggio G, Ding J, et al; WHO Research Group on Postovulatory Methods of Fertility Regulation. Low dose mifepristone and two regimens of levonorgestrel for emergency contraception: a WHO multicentre randomised trial. Lancet. 2002;360:1803-1810.

32. Cheng L, GülmezogluAM, Piaggio G, Ezcurra E, Van Look PF. Interventions for emergency contraception. Cochrane Database Syst Rev. 2008(2):CD001324.

33. Faculty of Sexual and Reproductive Health Care Clinical Effectiveness Unit. Quick Starting Contraception. 2010. Available from: http://www. fsrh.org/pdfs/CEUguidanceEmergencyContraception11.pdf. Accessed May 30, 2014.

34. Cameron ST, Glasier A, Johnstone A, Rae L. Ongoing contraception after use of emergency contraception from a specialist contraceptive service. Contraception. 2011;84:368-371.

35. Mohllajee AP, Curtis KM, Peterson HB. Does insertion and use of an intrauterine device increase the risk of pelvic inflammatory disease among women with sexually transmitted infection? A systematic review. Contraception. 2006;73(2);145-153.

36. Farley TM, Rosenberg MJ, Rowe PJ, Chen JH, Meirik O. Intrauterine devices and pelvic inflammatory disease: an international perspective. Lancet. 1992;339(8796):785-788.

37. Grimes DA. Intrauterine device and upper-genital-tract infection. Lancet. 2000;356(9234):1013-1019.

38. Bayer LL, Jensen JT, Li H, Nichols MD, Bednarek PH. Adolescent experience with intrauterine device insertion and use: a retrospective cohort study. Contraception. 2012;86:443-451.

39. Lader D. Opinions survey report no 41. Contraception and Sexual Health, 2008-9. Office for National Statistics; 2009.

40. Michie L, Cameron ST, Glasier A, Wellings K, Loudon J. Myths and misconceptions about intrauterine contraception among women seeking termination of pregnancy. J Fam Plann Reprod Health Care. 2014;40: 36-40.

41. Baird AS. Use of ulipristal acetate, levonorgestrel and the copperintrauterine device for emergency contraception following the introduction of new FSRH guidelines. J Fam Plann Reprod Health Care. 2013;39:264-269.

42. Ziebland S, et al. "It's a mega dose of hormones, isn't it?". Why women may be reluctant to use emergency contraception. Br J Fam Plann. 1996;22:84-86.

43. McKay R, Gilbert L. An emergency contraception algorithm based on risk assessment: changes in clinician's practice and patient's choices. $J$ Fam Plann Reprod Health Care. 2013;39(3)201-206.

44. Asker C, Stokes-Lampard H, Beavan J, Wilson S. What is it about intrauterine devices that women find unacceptable? Factors that make women non-users: a qualitative study. J Fam Plann Reprod Health Care. 2006;32(2):89-94.

45. Glasier A. Attitudes of women in Scotland to contraception: a qualitative study to explore the acceptability of long-acting methods. J Fam Plann Reprod Healthcare. 2008;34(4):213-217.

46. d'Arcangues C. Worldwide use of intrauterine devices for contraception. Contraception. 2007;75(Suppl 6):S2-S7.

47. Espey E, Singh RH, Leeman L, Ogburn T, Fowler K, Greene H. Misoprostol for intrauterine device insertion in nulliparous women: a randomized controlled trial. Am J Obstet Gynecol. 2014;210(3):208. e1-e5.

48. Bahamondes L, Mansour D, Fiala C, Kaunitz AM, Gemzell-Danielsson K. Practical advice for avoidance of pain associated with insertion of intrauterine contraceptives. J Fam Plann Reprod Health Care. 2014;40(1):54-60.

49. Moreau C, Bouyer J, Goulard H, Bajos N. The remaining barriers to the use of emergency contraception: perception of pregnancy risk by women undergoing induced abortions. Contraception. 2005;71:202-207.

50. Wright RL, Frost CJ, Turok DK. A qualitative exploration of emergency contraception users' willingness to select the copper IUD. Contraception. 2012;85:32-35. 
51. Schwarz EB, Kavanaugh M, Douglas E, Dubowitz T, Creinin MD. Interest in intrauterine contraception among seekers of emergency contraception and pregnancy testing. Obstet Gynecol. 2009;113:833-839.

52. Bharadwaj P, Saxton JC, Mann SN, Jungmann EM, Stephenson JM. What influences young women to choose between the emergency contraceptive pill and an intrauterine device? A qualitative study. Eur J Contracept Reprod Health Care. 2011;16:201-209.

53. Turok DK, Gurtcheff SE, Handley E, et al. A survey of women obtaining emergency contraception: are they interested in using the copper IUD? Contraception. 2011;83:441-446.

54. International Consortium for Emergency Contraception [homepage on the Internet]. New York, NY: International Consortium for Emergency Contraception. Available from: http://www.cecinfo.org. Accessed April 30, 2014.

55. Rodriguez MI, Curtis KM, Gaffield ML, Jackson E, Kapp N. Advance supply of emergency contraception: a systematic review. Contraception. 2013;87:590-601.

56. Polis CB, Schaffer K, Blanchard K, Glasier A, Harper CC, Grimes DA. Advance provision of emergency contraception for pregnancy prevention (full review). Cochrane Database Syst Rev. 2007;(2):CD005497.

57. Raymond EG, Trussell J, Polis CB. Population effect of increased access to emergency contraceptive pills: a systematic review. Obstet Gynecol. 2007;109(1):181-188.

58. Glasier A, Manners R, Loudon JC, Muir A. Community pharmacists providing emergency contraception give little advice about future contraceptive use: a mystery shopper study. Contraception. 2010;82: $538-542$

59. Clement KM, Mansour D. Improving uptake of the copper intrauterine device for emergency contraception by educating pharmacists in the community. J Fam Plann Reprod Health Care. 2014;40:41-45.
60. Bannister L, Macve J, Pinkey B, Webberley H. Is the faculty of family planning and reproductive health care guidance on emergency contraception being followed in general practice? An audit in the West Midlands, UK. J Fam Plann Reprod Health Care. 2007:33(3):195-198.

61. Harper CC, Speidel JJ, Drey EA, Trussell J, Blum M, Darney PD. Copper intrauterine device for emergency contraception: clinical practice among contraceptive providers. Obstet Gynecol. 2012;119(2 Pt 1):220-226.

62. McKay RJ, Gilbert L. Comment on 'an emergency contraception algorithm based on risk assessment: changes in clinicians' practice and patients' choices': authors' response. Fam Plann Reprod Health Care. 2013;39:231.

63. Singh S, Sedgh G, Hussain R. Unintended pregnancy: worldwide levels, trends, and outcomes. Stud Fam Plann. 2010;41(4):241-250.

64. Grimes DA, Benson J, Singh S, et al. Unsafe abortion: the preventable pandemic. Lancet. 2006;368(9550):1908-1919.

65. Mohllajee AP, Curtis KM, Morrow B, Marchbanks PA. Pregnancy intention and its relationship to birth and maternal outcomes. Obstet Gynecol. 2007;109:678-686.

66. Gipson JD, Koenig MA, Hindin MJ. The effects of unintended pregnancy on infant, child and parental health: a review of the literature. Stud Fam Plann. 2008;39(1):18-38.

67. Shah PS, Balkhair T, Ohlsson A, Beyene J, Scott F, Frick C. Intention to become pregnant and low birth weight and preterm birth: a systematic review. Matern Child Health J. 2011;15(2):205-216.

68. Baram I, Weinstein A, Trussell J. The IUB, a newly invented IUD: a brief report. Contraception. 2014;89(2):139-141.
Open Access Journal of Contraception

\section{Publish your work in this journal}

Open Access Journal of Contraception is an international, peerreviewed, open access, online journal, publishing original research, reports, reviews and commentaries on all areas of contraception. In addition to clinical research, demographics and health-related aspects, the journal welcomes new findings in animal and preclinical studies

\section{Dovepress}

relating to understanding the biological mechanisms and practical development of new contraceptive agents. The manuscript management system is completely online and includes a very quick and fair peer-review system. Visit http://www.dovepress.com/testimonials.php to read real quotes from published authors. 